\title{
Performance evaluation of a hybrid vehicle and sensor network to prevent traffic accidents
}

\author{
Autores \\ Jesús Silva, Noel Varela, Omar Bonerge Pineda Lezama
}

\begin{abstract}
In recent years, wireless networks have become a widespread communication technology as well as a research challenge. Many contributions have been made on ad hoc networks, such as wireless sensor networks (WSNs) and vehicular ad hoc networks (VANETs). Recently, the number of cars on our streets, roads, and highways has been increasing, giving rise to a great interest in vehicular communication technologies. This paper presents an hybrid sensor and vehicular network (HSVN) platform, as well as the description and evaluation of a communication protocol between VANETs and WSNs using a network simulator for its evaluation.

\section{Palabras clave}

Hybrid sensor and vehicular network (HSVN), Vehicular ad hoc networks (VANETs), Wireless sensor networks (WSNs)
\end{abstract}

